\title{
Interannual and Seasonal Shift between Microcystis and Dolichospermum: A 7-Year Investigation in Lake Chaohu, China
}

\author{
Min Zhang ${ }^{1,2, *}$, Zhen Yang ${ }^{1,2}$, Yang Yu ${ }^{1}$ and Xiaoli Shi ${ }^{1,2}$ \\ 1 State Key Laboratory of Lake Science and Environment, Nanjing Institute of Geography and Limnology, \\ CAS, Nanjing 210008, China; zhyang@niglas.ac.cn (Z.Y.); yyu@niglas.ac.cn (Y.Y.); xlshi@niglas.ac.cn (X.S.) \\ 2 Jiangsu Collaborative Innovation Center of Regional Modern Agriculture \& Environmental Protection, \\ Huaiyin Normal University, Huaian 223001, China \\ * Correspondence: mzhang@niglas.ac.cn; Tel.: +86-25-86882242
}

Received: 3 June 2020; Accepted: 9 July 2020; Published: 13 July 2020

\begin{abstract}
The shifts among bloom-forming cyanobacteria have attracted increasing attention due to the reductions in nitrogen and phosphorus during the eutrophication mitigation process. However, knowledge is limited regarding the pattern and drivers of the shifts among these cyanobacterial genera. In this study, we performed a 7-year long, monthly investigation in Lake Chaohu, to analyze the interannual and seasonal shifts between Microcystis and Dolichospermum. Our results showed that Microcystis was the dominant cyanobacterium in the western lake region in summer, whereas Dolichospermum was dominant in the other regions and seasons. The Microcystis biomass and ratio were driven primarily by total phosphorus and temperature. The sensitivity of Dolichospermum to nutrients and temperature was relatively weak compared to that of Microcystis. The shifts between Microcystis and Dolichospermum might be led by Microcystis. If the temperature and phosphorus level were relatively high, then Microcystis grew rapidly, and competitively excluded Dolichospermum. If the nutrient level, especially the phosphorus level, was low, then the exclusive power of Microcystis was weak, and Dolichospermum maintained its dominance, even in summer. The key temperature $\left(\sim 17^{\circ} \mathrm{C}\right)$ determined the dominance of the two cyanobacteria. Microcystis never dominated, while Dolichospermum was always dominant below the key temperature. Microcystis and Dolichospermum had different means of responding to the interaction of temperature, nitrogen and phosphorus. The Dolichospermum biomass was sensitive to the variation in nitrogen level, and the sensitivity depended on temperature. While the Microcystis biomass was sensitive to the variation in phosphorus level, and the sensitivity depended on temperature and total nitrogen. The different ways might contribute to the succession of the two cyanobacteria. Our findings will be helpful for improving the understanding of the shift process between Microcystis and Dolichospermum.
\end{abstract}

Keywords: Microcystis; Dolichospermum; Lake Chaohu; seasonal shift

\section{Introduction}

Cyanobacteria often dominate a phytoplankton community, and even form harmful algal blooms in eutrophic freshwaters, such as lakes, reservoirs and estuaries. The bloom-forming cyanobacteria are principally gas-vacuolate species. They are distributed across a number of genera, and vary in form and size from small filaments, such as Dolichospermum or Oscillatoria, to large globular colonies, such as Microcystis [1]. The most common bloom-forming cyanobacteria in these water bodies are Microcystis, Dolichospermum (Anabaena) and Aphanizomenon [2]. Generally, different bloom-forming cyanobacteria can co-occur or successively dominate at an intra-annual scale in a specific water body [3,4]. The temporal and spatial dynamics of bloom-forming cyanobacteria is considered to be a 
result of the synergistic effects of multiple driving forces [5,6]. However, our understanding of the succession patterns of bloom-forming species, and their underlying mechanics, is limiting.

Temperature is usually considered the primary driver of seasonal succession among cyanobacterial genera or species, due to the differences in their temperature niches $[4,7,8]$. The average temperatures at which Microcystis dominated were significantly higher than the temperatures at which Dolichospermum and Aphanizomenon were the most abundant [9]. Li and Watanabe [10] found that most of the Dolichospermum species had optimal growth when the temperature was above $20^{\circ} \mathrm{C}$. The optimal growth temperatures of some Dolichospermum species are similar to those of Microcystis under optimal nutrient conditions, but the maximal growth rates of Microcystis are higher than those of Dolichospermum [11,12]. In addition, low temperatures limited Microcystis more severely than Dolichospermum $[13,14]$. These findings regarding temperature niches were closely correlated with these species seasonally occurring or dominating in the field. For example, $\mathrm{N}_{2}$-fixing Aphanizomenon and Dolichospermum generally proliferate in early spring or late fall when the temperature is relatively low. Nondiazotrophic Microcystis occurs principally in midsummer, when the temperature is relatively high $[4,15]$. However, the seasonal correlation was also often altered by some exceptional observations. For example, dominant Dolichospermum was often observed in the eastern region of Lake Chaohu in summer $[9,16]$. The diazotrophic cyanobacteria Aphanizomenon appeared and formed a bloom in summer, and a Microcystis bloom was formed in winter in Lake Kinneret [17]. Therefore, the intra-annual shift in dominant cyanobacteria cannot be completely explained by temperature.

The availability of nutrients also plays an important role in this shift. Diazotrophic cyanobacteria can fix atmospheric $\mathrm{N}_{2}$ into biologically available $\mathrm{NH}_{3}$ in order to satisfy their nitrogen requirements for growth [18]. They are usually dominant when the total nitrogen to total phosphorus (TN/TP) ratio is low, or when nitrogen is limiting [19]. Nondiazotrophic cyanobacteria require chemically bound nitrogen source, and generally dominate when it is in excess [20]. Hence, controlling N inputs could actually aggravate the dominance of $\mathrm{N}$-fixing cyanobacteria $[18,21]$, and result in the shift from nondiazotrophic to diazotrophic cyanobacteria. However, at the intra-annual scale, the nitrogen concentration is high in spring or early summer, and low in summer and autumn, in productive temperate lakes [22]. During this period, a typical pattern involves diazotrophs, such as Aphanizomenon or Dolichospermum, occurring first, followed by nondiazotrophic genera, most notably Microcystis [23]. This seems to be in contrast with the pattern by which diazotrophs are expected to dominate when nitrogen levels are low [24]. In addition, the phosphorus strategy of bloom-forming cyanobacteria (Dolichospermum and Microcystis) is also considered one of the reasons for their shift. Rapid uptake and polyphosphate body accumulation in Microcystis guarantees their growth under low phosphorus conditions, and increases the phosphorus deficiency in Dolichospermum [25]. However, this mechanism is not able to explain the dominance of diazotrophic cyanobacteria in summer, which were not replaced by Microcystis $[9,17]$.

There is strong evidence that the relative importance of temperature and nutrients in promoting cyanobacteria is taxon-dependent. Some taxa, such as Dolichospermum, are more sensitive to nutrients, while others, such as Microcystis, are more sensitive to temperature [26]. The strategic difference might explain the counterintuitive patterns in the shifts among cyanobacterial genera in response to temperature and nutrients. However, our understanding of how the responses of these cyanobacterial genera to one variable depend on another variable is limiting.

To gain more insight into the relationship between temperature, nutrients, and the dominance of specific bloom-forming cyanobacterial genera, we conducted a monthly investigation from 2012 to 2018 in Lake Chaohu, to analyze the interannual and seasonal shift between Microcystis and Dolichospermum. Our aim was to answer the following two questions: (1) What is the difference between the two cyanobacteria with regards to their response to temperature and nutrients? (2) What are the key values of these variables that result in their shift? First, the variations in their biomass and ratios to total biomass were determined. Second, the main predictors, and the key values of the ratios of Microcystis and Dolichospermum to total algal biomass, were measured with classification and regression 
tree analysis. Finally, the mutual dependence of their responses to nitrogen or phosphorus, and the dependence on temperature, were analyzed and discussed.

\section{Materials and Methods}

\subsection{Study Lake}

Lake Chaohu is the fifth largest freshwater lake in China, and is located in central Anhui Province (Figure 1). It covers a catchment area of approximately $9200 \mathrm{~km}^{2}$, and has a surface of approximately $750 \mathrm{~km}^{2}$. The volume of Lake Chaohu can change dramatically from $17.2 \times 10^{8} \mathrm{~m}^{3}$ in the dry season to $32.3 \times 10^{8} \mathrm{~m}^{3}$ in the rainy season [27]. The maximum lake depth is approximately $6 \mathrm{~m}$ and mean depth is approximately $3 \mathrm{~m}$. In the lake, the submerged vegetation abruptly disappeared in 1963 due to the installation of the Chaohu sluice, and strong cyanobacterial blooms (primarily Microcystis and Dolichospermum) have been observed, attributing to aggravated eutrophication since the 1980s [28-31].

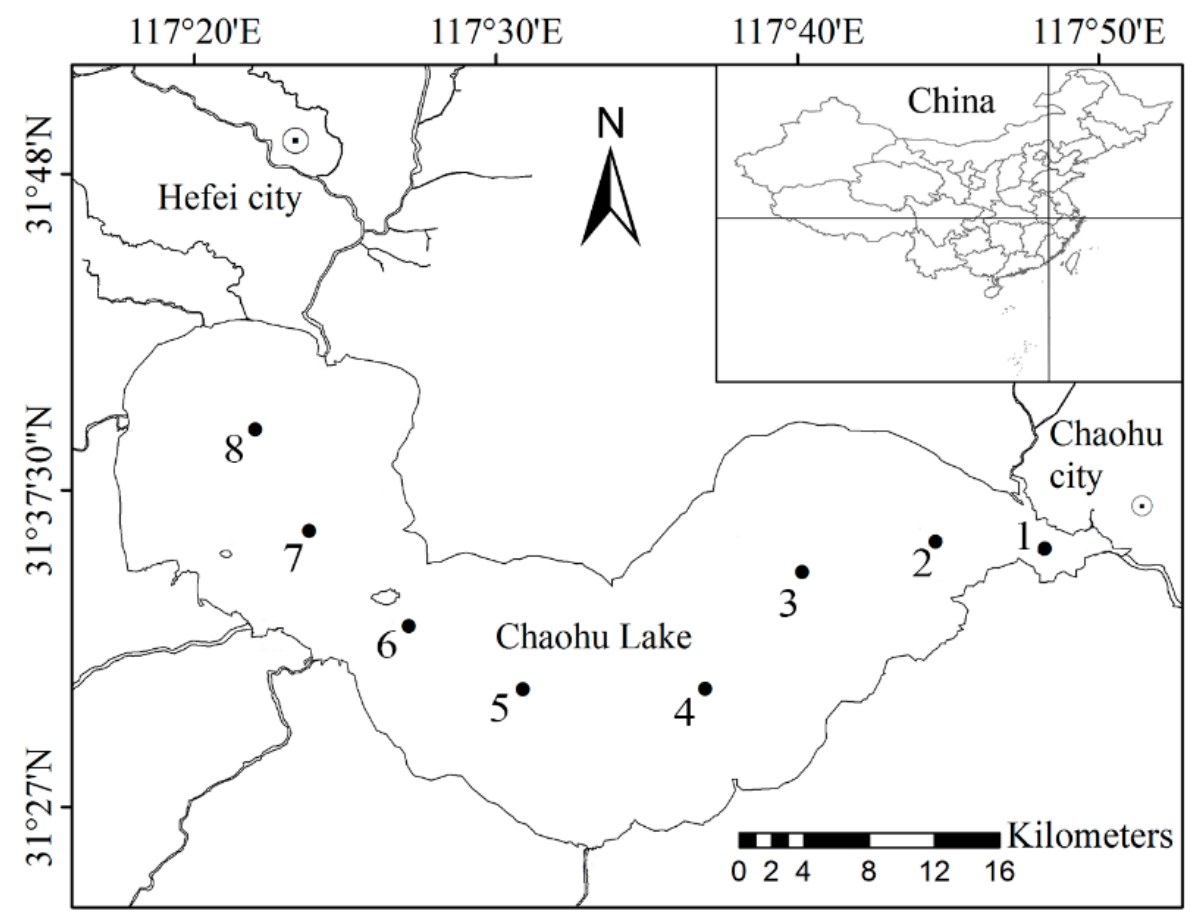

Figure 1. Map of Lake Chaohu showing the locations of 8 sampling sites.

\subsection{Sampling and Environmental Analyses}

To investigate the spatial-temporal distribution of bloom-forming cyanobacteria, we performed a monthly field investigation of 8 sites (eastern region: site 1, 2 and 3; central region: site 4, 5 and 6; western region: site 7 and 8) from 2012 to 2018. Water samples were collected by mixing the surface ( $50 \mathrm{~cm}$ below the surface), middle and bottom (50 $\mathrm{cm}$ above the bottom) samples taken with an Uwitec water sampler (Uwitec, Mondsee, Austria). A total of 672 samples have been collected over the past seven years. Environmental parameters (temperature, $\mathrm{pH}$, conductivity and dissolved oxygen) were measured at every sampling site using a multiparameter meter. Total nitrogen (TN) and total phosphorus (TP) were analyzed by peroxydisulfate oxidation and spectrophotometric methods [32]. Ammonium $\left(\mathrm{NH}_{4}\right)$, nitrate $\left(\mathrm{NO}_{3}\right)$, nitrite $\left(\mathrm{NO}_{2}\right)$ and orthophosphate $\left(\mathrm{PO}_{4}\right)$ were measured using a continuous flow analyzer (Skalar SA 1000, Breda, the Netherlands). Transparency (SD) was measured with a Secchi disk. 


\subsection{Phytoplankton Analyses}

Integrated 500-mL samples were collected for phytoplankton analysis at each site. The samples were fixed with acid Lugol's solution. Phytoplankton were identified to genus or species based on the most recent literature [33]. Identification and counts were performed in more than 30 random fields in sedimentation chambers $(30 \mathrm{~mL})$ using a microscope [34]. The biovolume of each species at each site was calculated based on the mean value of the linear measurements in 30 cells and converted to volumes after approximation to standard geometric solids [35]. The biomass was determined and converted to fresh weight, assuming a specific gravity of $1 \mathrm{~g} / \mathrm{cm}^{3}$.

\subsection{Data Analysis}

Temporal variations in environmental variables $\left(\mathrm{TN}, \mathrm{TP}, \mathrm{NH}_{4}, \mathrm{NOx}\right.$ including $\mathrm{NO}_{3}$ and $\mathrm{NO}_{2}, \mathrm{PO}_{4}$ and SD) in three lake regions (eastern, central and western regions) were shown based on a 3-month moving average. The ratios of Microcystis and Dolichospermum biomass to total algal biomass and these environmental variables among lake regions or sites were compared with the Tukey HSD method. Prior to the analyses, data were checked for homogeneity of variances and normality.

To identify the main predictor variables of the Microcystis and Dolichospermum ratios in the total algal biomass, their fractions were determined and used to perform classification and regression tree analysis with the caret package in R. Before the analysis, we identified the collinear variables and selected a subset of variables based on inspection of the variance inflation factors (VIFs). Those variables that had a VIF > 10 (i.e., multiple collinear variables) were removed [36]. We trained the model with the machine learning algorithm 'rpart'. The models were tuned using the 'tuneGrid' function with maxdepth $=3$ and mincriterion $=0.95$. In addition, the dependence of the relationship between the ratios and TP, or TN, on TN or TP and temperature was also presented with the 'coplot' function.

\section{Results}

\subsection{Spatial-Temporal Variation in Microcystis, Dolichospermum and Environmental Variables}

\subsubsection{Spatial-Temporal Variation in Environmental Variables}

From 2012 to 2018, the TP and $\mathrm{PO}_{4}$ concentrations increased, and the increasing magnitude was higher in the central and eastern lake regions than in the western lake region (Figure 2a,c and Figure S1a,c). The TN concentration decreased in the western lake region and increased in the central and eastern lake regions (Figure $2 \mathrm{~b}$ and Figure $\mathrm{S} 1 \mathrm{~b}$ ). The $\mathrm{NH}_{4}$ concentration decreased remarkably in the three regions in 2015 (Figure 2d and Figure S1d). The trends in NOx in the central and eastern lake regions were similar to those in TN. However, the NOx concentration increased obviously before 2015, and remained relatively stable after that (Figure 2e and Figure S1e). The transparency in the three lake regions presented a decreasing trend, and the decreasing magnitude in the eastern lake region was higher than that in other regions (Figure $2 \mathrm{f}$ and Figure S1f).

Spatially, the TP, $\mathrm{PO}_{4}, \mathrm{TN}$ and NOx concentrations gradually decreased from the western to the eastern lake region. In contrast, the transparency gradually increased. There was no obvious difference in the $\mathrm{NH}_{4}$ concentration among the lake regions (Figure 3). 

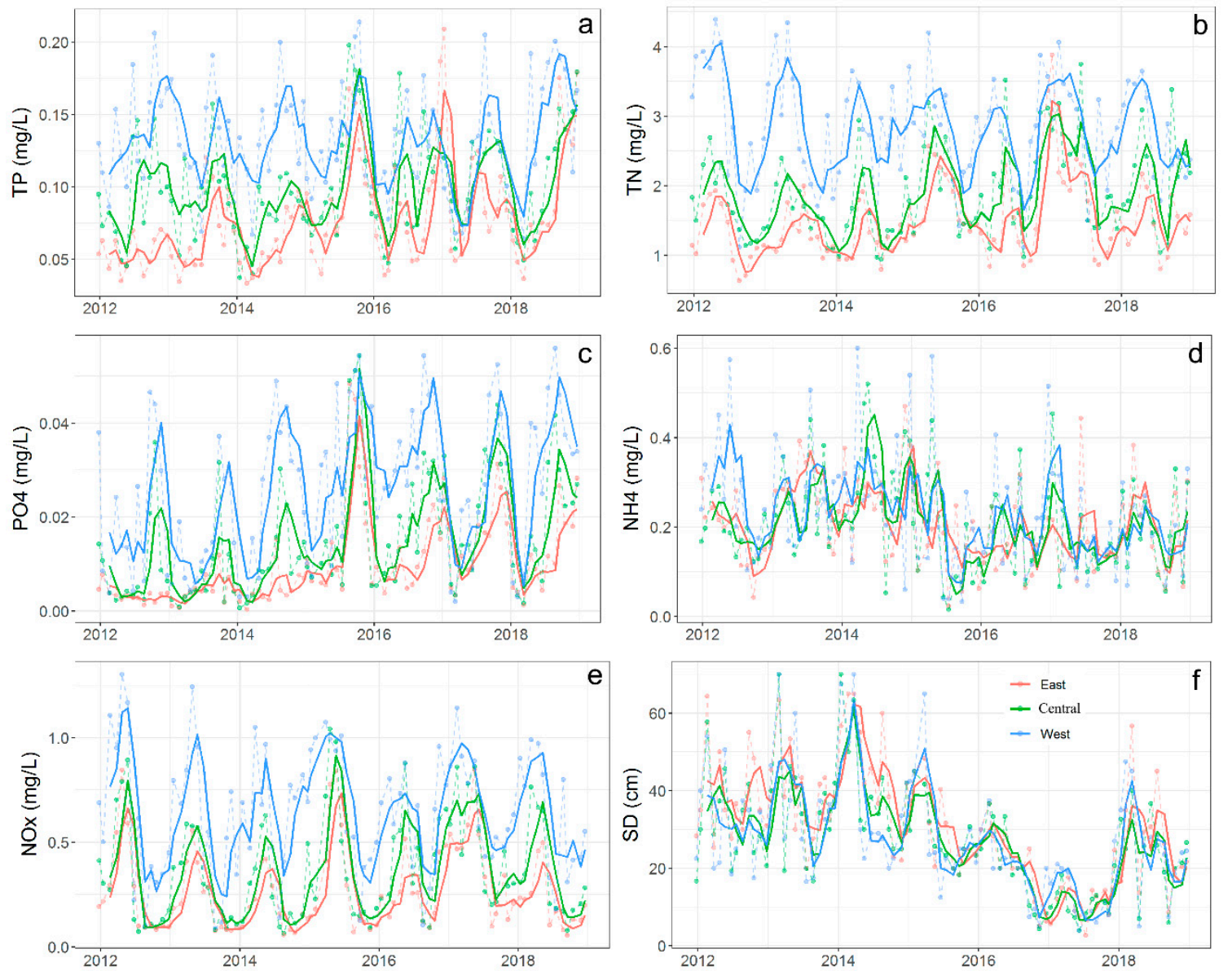

Figure 2. Long-term variations in the mean values of (a) total phosphorus (TP); (b) total nitrogen (TN), (c) orthophosphate $\left(\mathrm{PO}_{4}\right) ;(\mathbf{d})$ ammonium $\left(\mathrm{NH}_{4}\right)$; (e) nitrate + nitrite (NOx) and (f) transparency (SD) in the three lake regions of Lake Chaohu from 2012 to 2018. The solid lines represent the temporal trajectories based on a 3-month moving average.

\subsubsection{Spatial-Temporal Variation in Microcystis and Dolichospermum}

Dolichospermum flos-aquae and Microcystis spp. were identified as the dominant cyanobacteria in Lake Chaohu. For the past seven years, the Dolichospermum ratio has been higher than that of Microcystis in the whole lake. Dolichospermum dominated the eastern and central lake regions and Microcystis dominated the western lake region. The biomass of Microcystis showed obvious seasonal variation, and peaked in summer in all lake regions. Generally, the Microcystis ratios in the western region were higher than those in the central and eastern regions. However, the ratio showed an increasing trend in the eastern region (Figure 4a,b). The biomass of Dolichospermum generally peaked in late autumn, winter and early spring. There was a remarkable difference among the lake regions. The trend in the Dolichospermum ratio showed a decreasing trend (Figure $4 \mathrm{c}, \mathrm{d}$ ). 

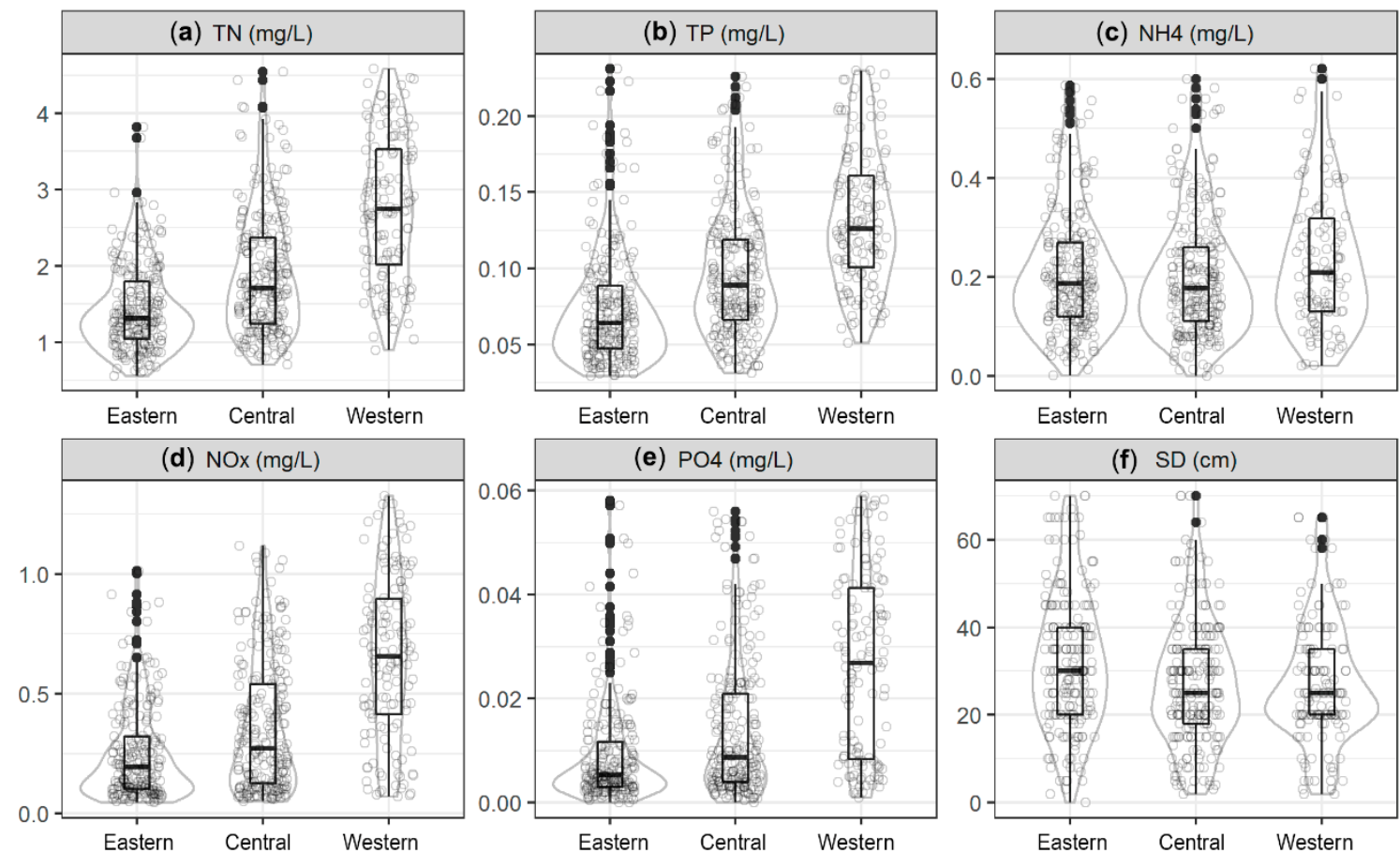

Figure 3. Values of (a) total nitrogen (TN), (b) total phosphorus (TP), (c) ammonium $\left(\mathrm{NH}_{4}\right)$, (d) nitrate + nitrite (NOx), (e) orthophosphate $\left(\mathrm{PO}_{4}\right)$ and (f) transparency $(\mathrm{SD})$ in the three lake regions of Lake Chaohu from 2012 to 2018. Whiskers represent the minimum and maximum values. Boxes symbolize the 25 th and 75 th percentiles. Lines inside the boxes show the median values. The black points show the outliers. The grey polygons show the distribution of the data along the Y-axis.

\subsection{Predictors and their key values of Microcystis and Dolichospermum Ratios to Total Biomass}

Water temperature (WT) was the dominant factor for the Microcystis ratio (Figure 5; node 1). When the WT was lower than $17.24^{\circ} \mathrm{C}$, the Microcystis ratio was generally low. Within this partition, an additional separating factor was TP concentration (Figure 5; nodes 2, 3). Low concentrations of $\mathrm{TP}(\leq 0.13 \mathrm{mg} / \mathrm{L})$ reduced the Microcystis ratio to less than $10 \%$. If the TP concentrations were higher than $0.13 \mathrm{mg} / \mathrm{L}$, then the Microcystis ratio was approximately $0-30 \%$. When the WT exceeded $17.24{ }^{\circ} \mathrm{C}$, the Microcystis ratio in most samples was high. TP and TN were additional separating factors in this section (Figure 5, nodes 7, 8). If the TP concentrations were higher than $0.125 \mathrm{mg} / \mathrm{L}$, then the Microcystis ratio could reach approximately $30-80 \%$. At a TP concentration of $\leq 0.125 \mathrm{mg} / \mathrm{L}$, TN or TN/TP was important to the Microcystis ratio. When TN $>1.51 \mathrm{mg} / \mathrm{L}$ or TN/TP $>12.08$, the Microcystis ratio in most samples was limited to $<15 \%$. When $\mathrm{TN} \leq 1.51 \mathrm{mg} / \mathrm{L}$ or TN/TP $\leq 12.08$, the Microcystis ratio in most samples was approximately $10-60 \%$. 

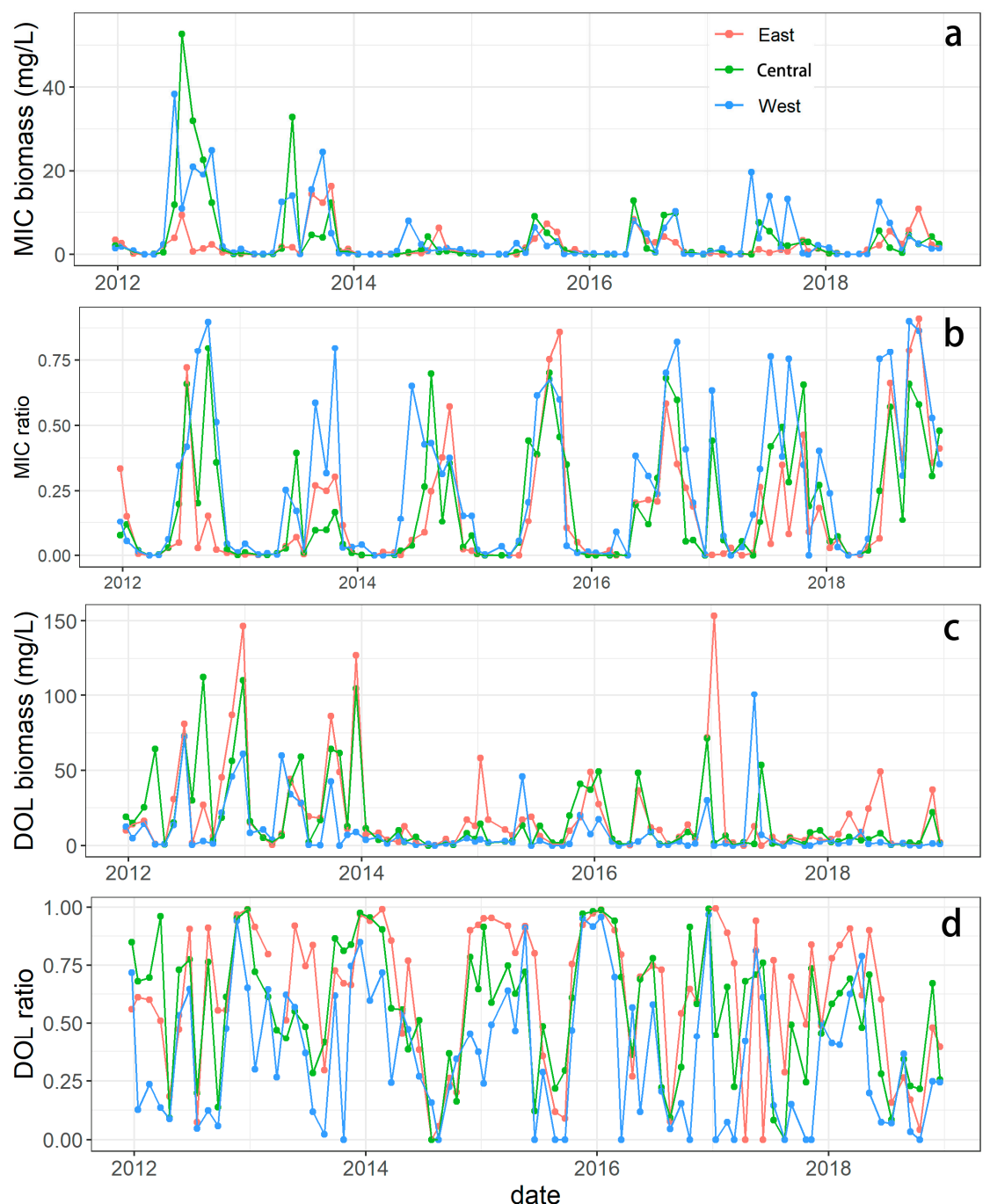

Figure 4. Variations in Microcystis (MIC) biomass (a), Dolichospermum (DOL) biomass; (c) and their ratios to the total biomass (b) and (d) from 2012 to 2018 in Lake Chaohu. The colored points and lines indicate different lake regions.

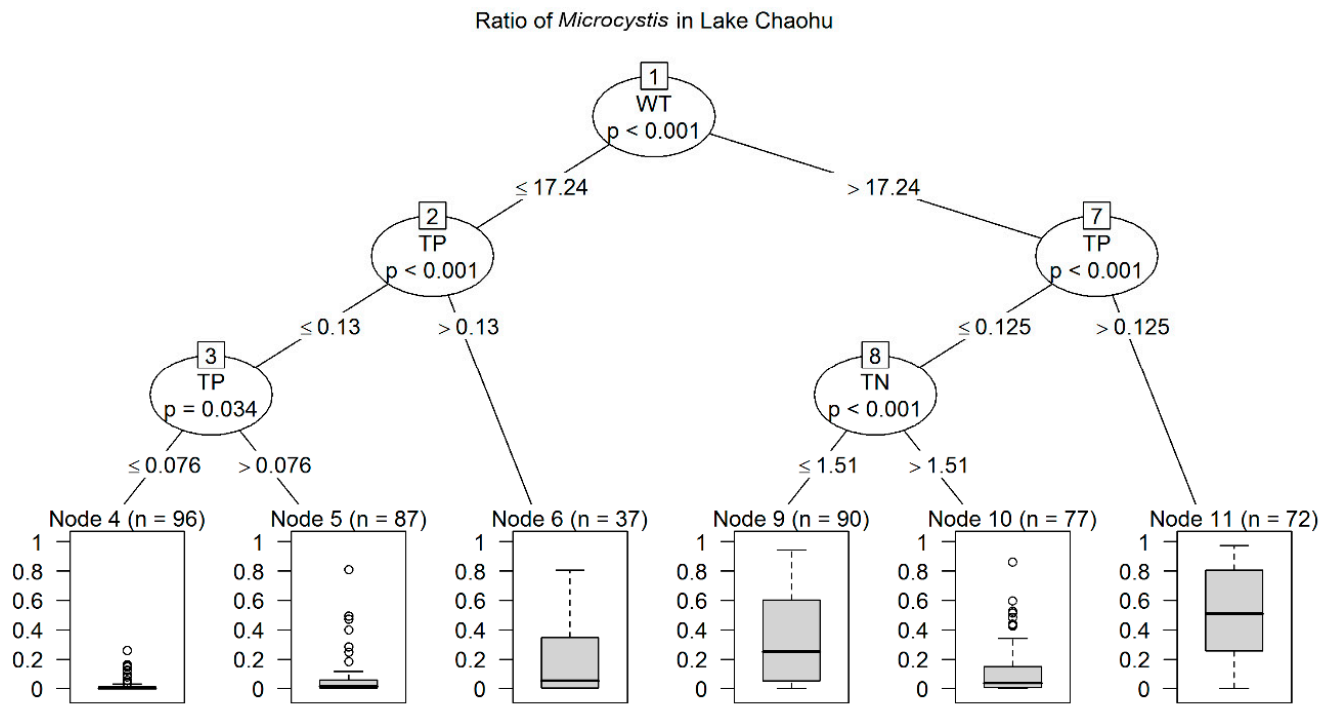


Figure 5. Classification trees for the ratio of Microcystis to total biomass. The extracted predictor variables represent the link: TN, total nitrogen $(\mathrm{mg} / \mathrm{L})$; $\mathrm{TP}$, total phosphorus $(\mathrm{mg} / \mathrm{L})$; and WT, water temperature $\left({ }^{\circ} \mathrm{C}\right)$.

WT was also a crucial factor for the Dolichospermum ratio (Figure 6; node 1). When the WT was lower than $16.63{ }^{\circ} \mathrm{C}$, the Dolichospermum ratio was generally high. The TN concentration was an additional separating factor within this partition (Figure 6; nodes 2). Low concentrations of TN $(\leq 2.173 \mathrm{mg} / \mathrm{L})$ increased the Dolichospermum ratio to more than $70 \%$. When the TN concentrations were higher than $2.173 \mathrm{mg} / \mathrm{L}$, the Dolichospermum ratio was approximately $20-80 \%$, and the median was approximately $50 \%$. When WT exceeded $16.63^{\circ} \mathrm{C}$, TP and WT became additional separating factors. If TP $>0.063 \mathrm{mg} / \mathrm{L}$ and $\mathrm{WT}>25.285^{\circ} \mathrm{C}$, then the Dolichospermum ratio was limited to $<40 \%$. If TP $>0.063 \mathrm{mg} / \mathrm{L}$ and WT $\leq 25.285{ }^{\circ} \mathrm{C}$, then the median Dolichospermum ratio increased to $40 \%$. At a TP concentration of $\leq 0.063 \mathrm{mg} / \mathrm{L}$, the median Dolichospermum ratio was as high as $60 \%$.

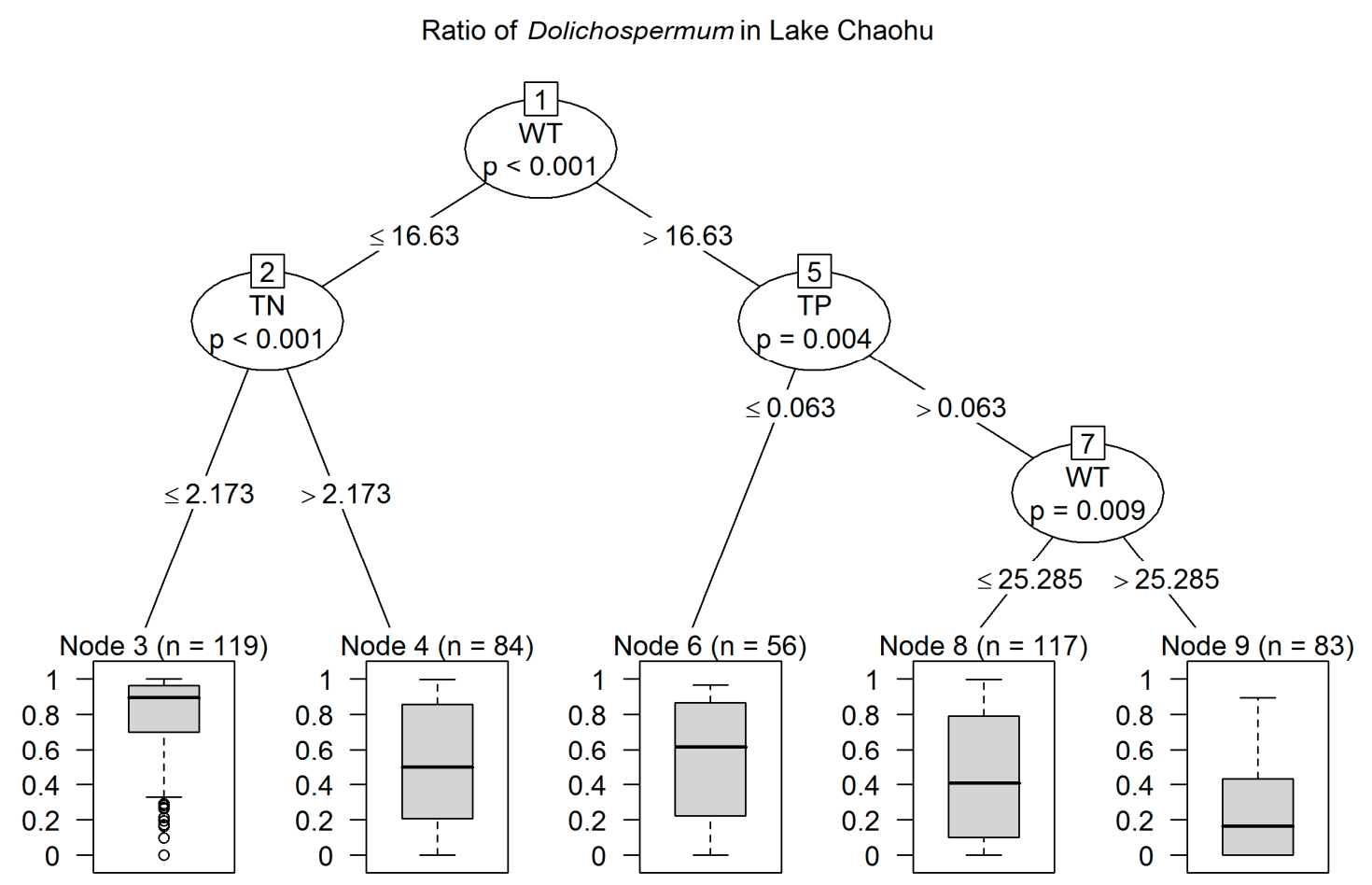

Figure 6. Classification trees for the ratio of Dolichospermum to total biomass. The extracted predictor variables represent the link: TN, total nitrogen $(\mathrm{mg} / \mathrm{L})$; $\mathrm{TP}$, total phosphorus $(\mathrm{mg} / \mathrm{L})$; and $\mathrm{WT}$, water temperature $\left({ }^{\circ} \mathrm{C}\right)$.

WT was the most important factor for the two cyanobacterial ratios, and TN and TP were also key regulating factors. When the WT was less than $17^{\circ} \mathrm{C}$, the Dolichospermum ratio gradually decreased from the eastern to western lake region, and the Microcystis ratio was still low. When the WT was 17-25 ${ }^{\circ} \mathrm{C}$, the Dolichospermum and Microcystis ratios were close to each other in the western lake region, where the nutrient level was high. In the lake regions with relatively low nutrient levels, the Dolichospermum ratio was higher than the Microcystis ratio. When the WT was more than $25^{\circ} \mathrm{C}$, the Microcystis ratio exceeded that of Dolichospermum in the central and western lake regions. However, the Dolichospermum ratio was still higher than that of Microcystis in the eastern lake region (Figure 7). 

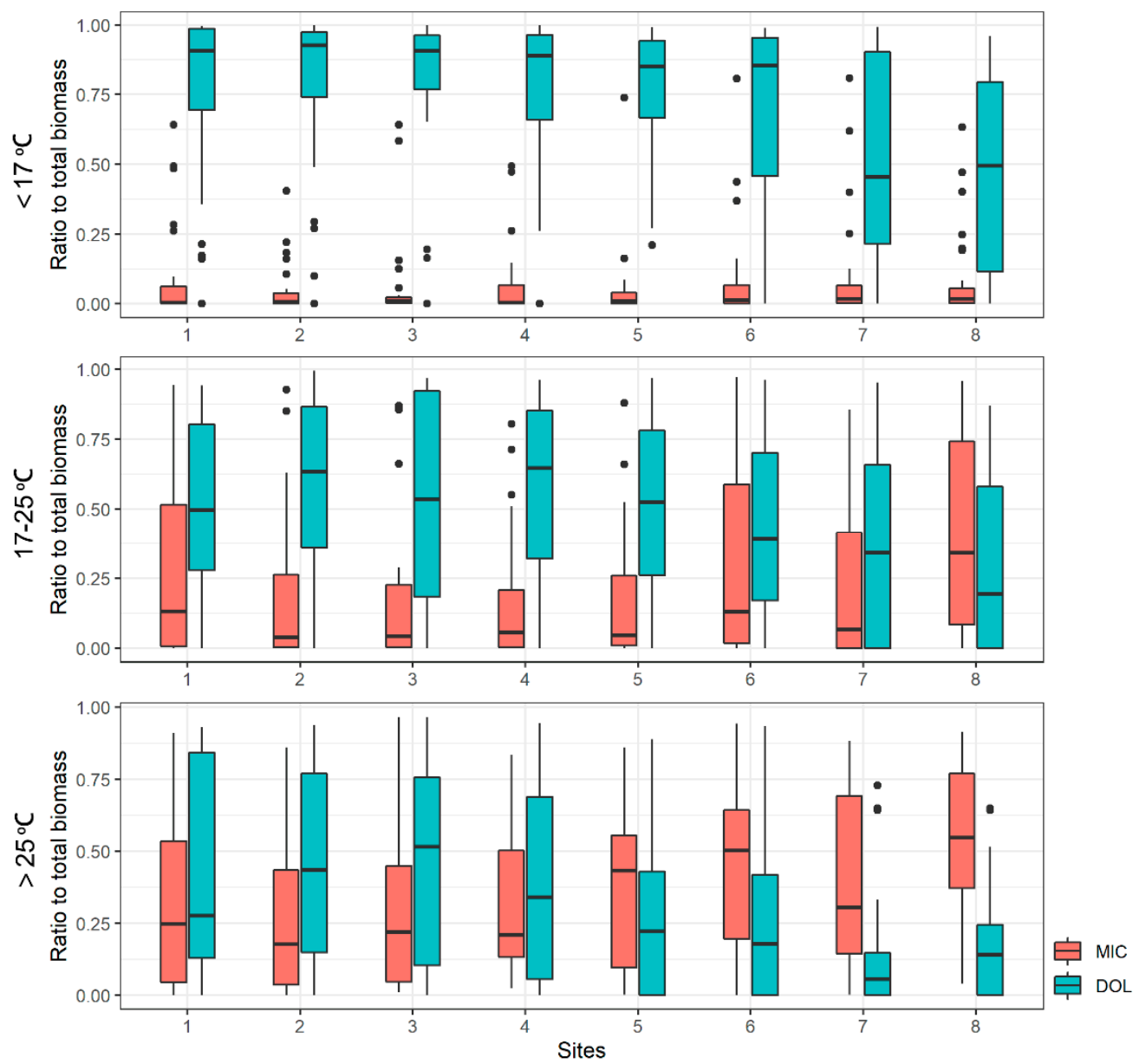

Figure 7. Ratios of Microcystis (MIC) and Dolichospermum (DOL) to total biomass at the difference sites of Lake Chaohu under different temperature conditions.

\subsection{Responses of Microcystis and Dolichospermum to Water Temperature, Nitrogen and Phosphorus}

There were significantly positive relationships between WT and Microcystis biomass at all TN and TP levels $(p<0.05$, Figure 8 ), and the slopes of the fitting lines were similar. The positive response of Microcystis biomass to TP increased with the increasing WT and TN level (Figure S2), while the negative biomass response to TN decreased with the increasing WT and TN level (Figure S3). The Microcystis ratios increased significantly with the increasing WT. The slopes of the relationship between the Microcystis ratio and WT increased with the increasing TP level, and almost did not change with the TN level. The relationship between the Dolichospermum biomass and WT only showed a significantly negative trend when the TP concentration was high (>ca. $0.10 \mathrm{mg} / \mathrm{L})$ and the TN concentration was low (<ca. $1.5 \mathrm{mg} / \mathrm{L}$ ) (Figure 9). When the WT was more than $20^{\circ} \mathrm{C}$, the Dolichospermum biomass was positively correlated with TN under high TP conditions, and had no relationship with TN under low TP conditions (Figure S4). There was no significant relationship between Dolichospermum biomass and TP under any of the TN conditions (Figure S5). The relationships between the Dolichospermum ratio and temperature were negative when TP was less than approximately $0.075 \mathrm{mg} / \mathrm{L}(p<0.05)$, or when $\mathrm{TP}$ was more than this value and TN was less than approximately $2.25 \mathrm{mg} / \mathrm{L}$. 


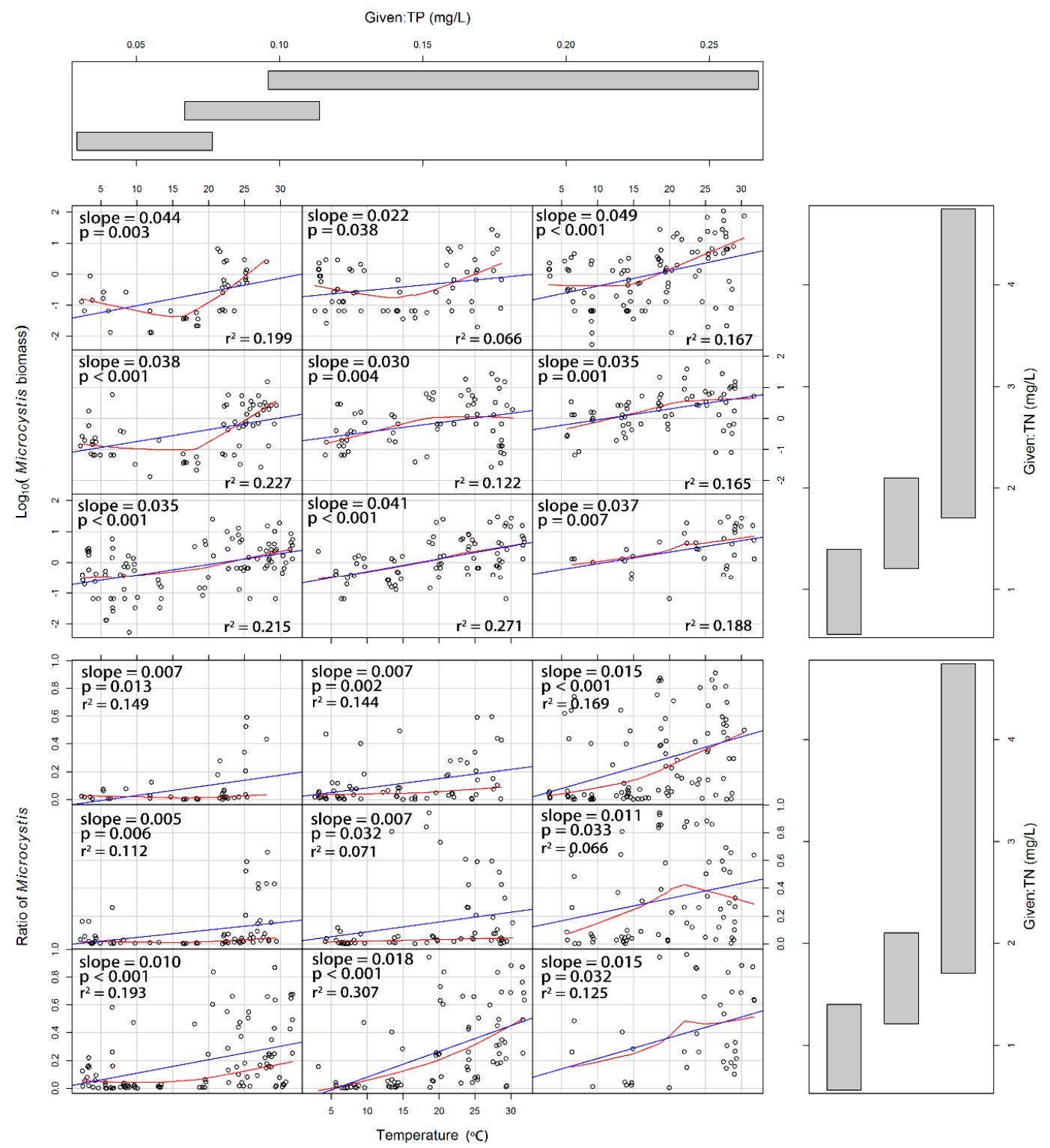

Figure 8. Relationships between temperature and Microcystis biomass (top) or ratios (bottom) depending on total nitrogen (TN) and total phosphorus (TP), which was divided into three segments, on average, of the data numbers with $30 \%$ overlap. The red and blue lines represent the LOESS and linear fits, respectively. The parameters of linear fit were shown in each panel. 


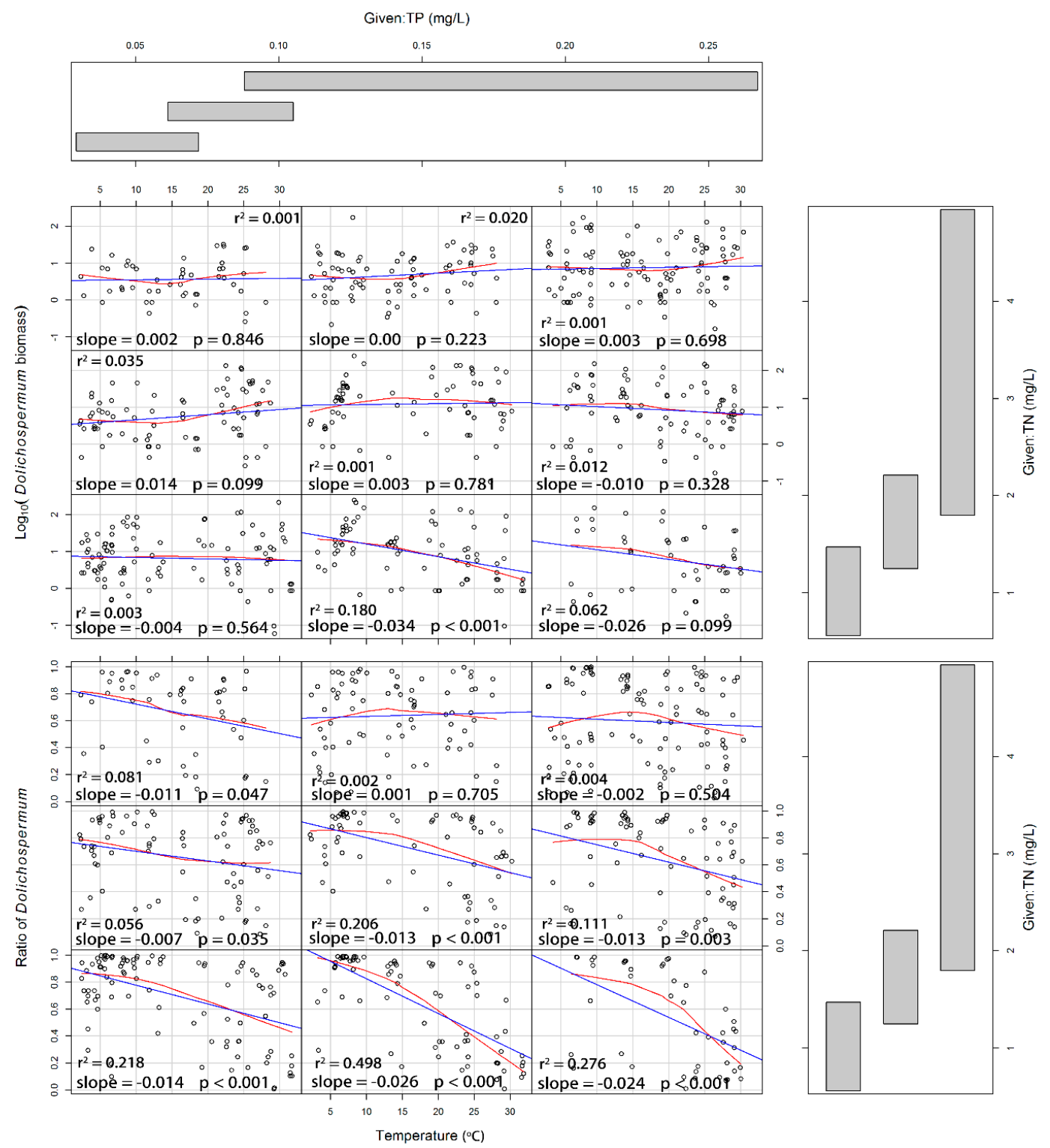

Figure 9. Relationships between water temperature and Dolichospermum biomass (top) or ratios (bottom) depending on total nitrogen (TN) and total phosphorus (TP), which was divided into three segments, on average, of the data numbers, with $30 \%$ overlap. The red and blue lines represent the LOESS and linear fits, respectively. The parameters of linear fit were shown in each panel.

\section{Discussion}

Recently, species succession among bloom-forming cyanobacteria has attracted increasing attention from researchers and managers of water bodies, and this succession varies with reductions of nitrogen and phosphorus during eutrophication mitigation process $[4,23,25]$. In this study, we performed a 7-year investigation of the spatial and temporal shifts between Microcystis and Dolichospermum in Lake Chaohu. We found that Microcystis mainly dominated the western region of the lake in summer, whereas Dolichospermum dominated in other regions and seasons. The shift between Microcystis and Dolichospermum in Lake Chaohu might be mostly led by Microcystis. If the temperature and phosphorus levels were relatively high, then Microcystis grew rapidly and competitively excluded Dolichospermum. If the nutrient levels, especially the phosphorus level, were low, then the exclusive power of Microcystis was weak, and Dolichospermum maintained its dominance, even on hot summer days. 


\subsection{Temperature}

Diazotrophs, such as Aphanizomenon, were replaced seasonally by nondiazotrophs, such as Microcystis, which have been observed in many waterbodies [8,21,37]. However, the shift from Dolichospermum to Microcystis often showed different patterns. Generally, the two species co-exist or dominate different regions of one water body [6]. Sometimes, their succession was also not complete, and even Dolichospermum could not be replaced by Microcystis in Lake Chaohu [9,25]. In the study, we confirmed the failed succession with a 7-year investigation. Generally, the shift in Microcystis may be attributed to temperature adaptations [7,23], and that of filamentous $\mathrm{N}_{2}$-fixing exhibited lake-specific responses [4]. We found that the Microcystis ratio increased, and the Dolichospermum ratio decreased, with increasing temperature and phosphorus levels, which was consistent with the previous findings that high temperature and phosphorus levels favor Microcystis dominance [13,14]. Li and Watanabe [10] found that most strains of Dolichospermum have a high optimal growth temperature, which was even similar to that of Microcystis, but the maximal growth rate of Microcystis was higher than that of Dolichospermum [11,12]. This may partially explain the high Microcystis biomass and the decrease in Dolichospermum biomass in summer. Bormans et al. found that the Dolichospermum population collapsed when the temperature was greater than $26^{\circ} \mathrm{C}$ in the field [38]. However, the collapse did not occur in the eastern lake region, even in summer, when the surface water temperature was over $26^{\circ} \mathrm{C}$. Therefore, in Lake Chaohu, temperature could explain the shift from Dolichospermum to Microcystis in the western region of the lake, but was not able to explain the dominance of Dolichospermum in the eastern region in summer. In the study, we also found that a key temperature $\left(\sim 17^{\circ} \mathrm{C}\right)$ will determine dominance of the two cyanobacteria. When the temperature was lower than the key temperature, Microcystis did not dominate the phytoplankton community. Whereas Dolichospermum was always the dominant cyanobacteria, and the ratio of Dolichospermum to total phytoplankton biomass might depend on nitrogen and phosphorus levels. Because the Dolichospermum ratio was low in the western lake region, where nitrogen and phosphorus levels were relatively high, the dominance of the two cyanobacteria appears to be determined by the interaction of nutrients and temperature, as the temperature here was higher than the key temperature.

\subsection{Nutirents}

The difference in the responses of the two cyanobacteria to phosphorus was also used to explain the shift from Dolichospermum to Microcystis. Wan et al. [25] found that during the process of replacement by Microcystis, Dolichospermum was adversely affected by phosphorus deficiency, while Microcystis never experienced $\mathrm{P}$ limitation due to its ability to rapidly take up and store phosphorus at low phosphorus levels. However, the phosphorus level was lower in the eastern region of Lake Chaohu than that in the western region. Although Microcystis had the advantage of using phosphorus, and increased the phosphorus deficiency of the coexisting phytoplankton species, the strategy did not support the pattern of Microcystis replacing Dolichospermum. Therefore, the phosphorus strategy might be insufficient to explain the dominance of Dolichospermum in the eastern lake region in summer. In addition, Dolichospermum was considered dominant when nitrogen was limiting or the TN/TP ratio was low, because Dolichospermum is able to fix $\mathrm{N}_{2}$ when nitrogen is in short supply [19]. However, few heterocysts were observed in the sample dominated by Dolichospermum, suggesting that the bioavailable nitrogen might have been sufficient, so it was unnecessary to fix nitrogen by heterocysts [9]. Therefore, the variations in the TN/TP ratio might not be the primary factor affecting the shifts between the two cyanobacteria in Lake Chaohu.

According to our results, there was a significant positive relationship between TP and Microcystis biomass. It is possible that Microcystis biomass was limited by the relatively low TP in the eastern lake region. In addition, the Microcystis ratio increased and the Dolichospermum ratio decreased over the long-term, which was mainly due to the increase of the Microcystis ratio in the eastern lake region [39]. Furthermore, the increase in the Microcystis ratio might have been the result of the increase in TP and $\mathrm{PO}_{4}$. The response of Dolichospermum biomass to temperature, TN and TP was weak when 
nutrients were relatively low. The differences of the two cyanobacteria responding to phosphorus might maintained the dominance of Dolichospermum in the eastern region of Lake Chaohu in summer. The accumulation of biomass might be more important than other factors in terms of the shift between Microcystis and Dolichospermum, which depends on their phosphorus uptake kinetics. The phosphorus kinetic parameters of Microcystis, including the maximal uptake rate $\left(\mathrm{V}_{\max }\right)$ and half-saturation constant for uptake (K), were higher than those of Dolichospermum [40]. The higher $\mathrm{V}_{\max }$ and $\mathrm{K}$ indicate that Microcystis has a higher phosphorus requirement, and its growth response is more sensitive to a relatively large range of phosphorus concentrations. This explained the increase in Microcystis biomass and the ratio at high phosphorus levels in the study. In addition, microcystin is considered the primary factor that controls the growth of Dolichospermum [41]. In the study, the microcystin level produced by Microcystis might not have been the adequate dose to inhibit Dolichospermum growth, because the microcystin content might have been reduced by low nitrogen and Dolichospermum [42]. Therefore, the relatively low Microcystis biomass was not able to overcome Dolichospermum dominance, even with the microcystin.

\subsection{Interaction among Temperature, Nitrogen and Phosphorus}

The interaction among nitrogen, phosphorus and temperature plays an important role in dominance formation and the succession of specific bloom-forming cyanobacteria $[5,26,43]$. As mentioned above, when temperature was lower than the key temperature $\left(\sim 17{ }^{\circ} \mathrm{C}\right)$, the Dolichospermum ratio might depend on the nitrogen and phosphorus levels. According to the relationship between Dolichospermum biomass and nutrients under low temperature conditions, the low Dolichospermum ratio might be mainly correlated to the high nitrogen level, not the phosphorus level. However, when the temperature was more than approximately $20^{\circ} \mathrm{C}$, the Dolichospermum biomass and ratio increased with the increasing TN concentration, but had no significant relationship with TP concentration. This result indicated that the responses of Dolichospermum to TN were opposite under low and high temperature conditions, and the response of Dolichospermum to TP was not sensitive (Figure S5). Regosi et al. found that Dolichospermum was more sensitive to nutrients [26]. Our findings further indicated that it was sensitive to nitrogen, and its response to TN depended on temperature.

The response of Microcystis biomass to TP depended on TN and temperature, and Microcystis biomass increased faster with increasing TP concentrations under a higher temperature and TN concentration comdition. However, its responses to TN and temperature did not depend (or did, but only weakly) on the other two variables according to the variation in the slopes of the relationships between Microcystis biomass and TN or temperature. These results suggested that although Microcystis biomass was affected directly by TN, TP and temperature, only the relationship between Microcystis biomass and TP was associated with TN and temperature. Our findings indicated that both Microcystis and Dolichospermum had different ways of responding to the interaction of temperature, nitrogen and phosphorus, which might contribute to their seasonal succession in Lake Chaohu.

\section{Conclusions}

Microcystis and Dolichospermum responded to variations in multiple environmental variables in multifaceted ways in the complex aquatic ecosystem of Lake Chaohu. From the perspective of the primary variables affecting cyanobacterial dynamics, it is evident that the shift between Microcystis and Dolichospermum in Lake Chaohu might be mostly led by Microcystis, depending on its response to temperature and phosphorus. However, the response of Dolichospermum was passive, due to its weak sensitivity to the variation in temperature and nutrients during the shift. Our results indicate that in eutrophic Lake Chaohu, minimizing phosphorus levels will lead to significant reductions in nondiazotroph Microcystis biomass. In addition, minimizing the nitrogen level will lead to significant reductions in the diazotroph Dolichospermum biomass at high temperatures and high phosphorus levels, and significant increases at low temperatures and low phosphorus levels. Our findings improve 
the understanding of the shifts between Microcystis and Dolichospermum in eutrophic lakes, and will be helpful for the control of eutrophication and the management of nutrient loadings.

Supplementary Materials: The following materials are available online at http://www.mdpi.com/2073-4441/12/ 7/1978/s1, Figure S1: Long-term trends in total phosphorus (TP), total nitrogen (TN), orthophosphate $\left(\mathrm{PO}_{4}\right)$, ammonium $\left(\mathrm{NH}_{4}\right)$, nitrate + nitrite (NOx) and transparency (SD) in the three lake regions of Lake Chaohu from 2012 to 2018. The solid lines represent the regression lines fitted with the LOESS. Figure S2: Relationships between total phosphorus and Microcystis biomass depending on total nitrogen and temperature, which was divided into three segments on average of the data numbers with 30\% overlap. The red and blue lines represent the LOESS and linear fits, respectively. The parameters of linear fit were shown in each panel. Figure S3: Relationships between total nitrogen and Microcystis biomass depending on total phosphorus and temperature, which was divided into three segments on average of the data numbers with $30 \%$ overlap. The red and blue lines represent the LOESS and linear fits, respectively. The parameters of linear fit were shown in each panel. Figure S4: Relationships between total phosphorus and Dolichospermum biomass depending on total nitrogen and temperature, which was divided into three segments on average of the data numbers with $30 \%$ overlap. The red and blue lines represent the LOESS and linear fits, respectively. The parameters of linear fit were shown in each panel. Figure S5: Relationships between total nitrogen and Dolichospermum biomass depending on total phosphorus and temperature, which was divided into three segments on average of the data numbers with $30 \%$ overlap. The red and blue lines represent the LOESS and linear fits, respectively. The parameters of linear fit were shown in each panel.

Author Contributions: Conceptualization, M.Z. and X.S.; investigation, Z.Y. and Y.Y.; data curation, M.Z.; writing —original draft preparation, M.Z.; writing — review and editing, M.Z. and X.S. All authors have read and agreed to the published version of the manuscript.

Funding: This work was supported by grants from the National Natural Science Foundation of China (31870447, 31570457), the Major Science and Technology Program for Water Pollution Control and Treatment (2017ZX07603-005, 2018ZX 07208-04), the KeyResearch Program of Frontier Sciences, CAS (Grant No. ZDBS-LY-DQC018) and the project of the 135 program of NIGLAS (NIGLAS2018GH03).

Acknowledgments: Thank Kuimei Qian for her assistance with phytoplankton identification.

Conflicts of Interest: The authors declare no conflict of interest.

\section{References}

1. Whitton, B.A.; Potts, M. The Ecology of Cyanobacteria: Their Diversity in Time and Space; Kluwer Scientific Publishers: Dordrecht, The Netherlands, 2000; pp. 150-151.

2. Paerl, H.W.; Fulton, R.S. Ecology of Harmful Cyanobacteria. In Ecology of Harmful Algae; Granéli, E., Turner, J.T., Eds.; Springer: Berlin/Heidelberg, Germany, 2006; Volume 189, pp. 95-109.

3. Reynolds, C.S. Cyanobacterial water-blooms. In Advances in Botanical Research; Callow, J., Ed.; Academic Press: London, UK, 1987; Volume 13, pp. 67-143.

4. Shan, K.; Song, L.; Chen, W.; Li, L.; Liu, L.; Wu, Y.; Jia, Y.; Zhou, Q.; Peng, L. Analysis of environmental drivers influencing interspecific variations and associations among bloom-forming cyanobacteria in large, shallow eutrophic lakes. Harmful Algae 2019, 84, 84-94. [CrossRef] [PubMed]

5. Dokulil, M.T.; Teubner, K. Cyanobacterial dominance in lakes. Hydrobiologia 2000, 438, 1-12. [CrossRef]

6. Oliver, R.; Ganf, G. Freshwater Blooms. In The Ecology of Cyanobacteria; Whitton, B., Potts, M., Eds.; Kluwer Academic Publishers: Dordrecht, Netherlands, 2000; pp. 149-194.

7. Takano, K.; Hino, S. Effect of temperature on the succession of planktonic algae in hypertrophic Lake Barato, Hokkaido. Jpn. J. Phycol. 1997, 45, 89-93.

8. Wu, Y.; Li, L.; Zheng, L.; Dai, G.; Ma, H.; Shan, K.; Wu, H.; Zhou, Q.; Song, L. Patterns of succession between bloom-forming cyanobacteria Aphanizomenon flos-aquae and Microcystis and related environmental factors in large, shallow Dianchi Lake, China. Hydrobiologia 2016, 765, 1-13. [CrossRef]

9. Zhang, M.; Zhang, Y.; Yang, Z.; Wei, L.; Yang, W.; Chen, C.; Kong, F. Spatial and seasonal shifts in bloom-forming cyanobacteria in Lake Chaohu: Patterns and driving factors. Phycol. Res. 2016, 64, 44-55. [CrossRef]

10. Li, R.; Watanabe, M.M. Physiological properties of planktic species of Anabaena (Cyanobacteria) and their taxonomic value at species level. Arch. Hydrobiol. (Suppl.) (Algol. Stud.) 2001, 140, 31-45. [CrossRef]

11. Nalewajko, C.; Murphy, T.P. Effects of temperature, and availability of nitrogen and phosphorus on the abundance of Anabaena and Microcystis in Lake Biwa, Japan: An experimental approach. Limnology 2001, 2, 45-48. [CrossRef] 
12. Crawford, K.A. The Effects of Nutrient Ratios and Forms on the Growth of Microcystis Aeruginosa and Anabaena Flos-Aquae. Master's Thesis, University of Vermont, Burlington, VT, USA, 2008.

13. Robarts, R.D.; Zohary, T. Temperature effects on photosynthetic capacity, respiration, and growth rates of bloom-forming cyanobacteria. N. Z. J. Mar. Freshw. Res. 1987, 21, 391-399. [CrossRef]

14. Ohkubo, N.; Yagi, O.; Okada, M. Studies on the succession of blue-green algae, Microcystis, Anabaena, Oscillatoria and Phormidium in Lake Kasumigaura. Environ. Technol. 1993, 14, 433-442. [CrossRef]

15. Moisander, P.H.; Paerl, H.W.; Zehr, J.P. Effects of inorganic nitrogen on taxa-specific cyanobacterial growth and nifH expression in a subtropical estuary. Limnol. Oceanogr. 2008, 53, 2519-2532. [CrossRef]

16. Wang, X.L.; Zhang, M.; Yin, J. Composition and influential factors of phytoplankton function groups in Lake Chaohu. J. Lake Sci. 2018, 30, 431-440.

17. Zohary, T. Changes to the phytoplankton assemblage of Lake Kinneret after decades of a predictable, repetitive pattern. Freshw. Biol. 2004, 49, 1355-1371. [CrossRef]

18. Schindler, D.W.; Hecky, R.E.; Findlay, D.L.; Stainton, M.P.; Parker, B.R.; Paterson, M.J.; Beaty, K.G.; Lyng, M.; Kasian, S.E.M. Eutrophication of lakes cannot be controlled by reducing nitrogen input: Results of a 37-year whole-ecosystem experiment. Proc. Natl. Acad. Sci. USA 2008, 105, 11254-11258. [CrossRef] [PubMed]

19. Reynolds, C.S. Ecology of Phytoplankton (Ecology, Biodiversity and Conservation); Cambridge University Press: Cambridge, UK, 2006.

20. Wejnerowski, Ł.; Rzymski, P.; Kokociński, M.; Meriluoto, J. The structure and toxicity of winter cyanobacterial bloom in a eutrophic lake of the temperate zone. Ecotoxicology 2018, 27, 752-760. [CrossRef] [PubMed]

21. Miller, T.R.; Beversdorf, L.; Chaston, S.D.; McMahon, K.D. Spatiotemporal molecular analysis of cyanobacteria blooms reveals Microcystis-Aphanizomenon interactions. PLoS ONE 2013, 8, e74933. [CrossRef]

22. Xu, H.; Paerl, H.W.; Qin, B.; Zhu, G.; Gao, G. Nitrogen and phosphorus inputs control phytoplankton growth in eutrophic Lake Taihu, China. Limnol. Oceanogr. 2010, 55, 420-432. [CrossRef]

23. Paerl,H.W.; Otten, T.G. Duelling 'CyanoHABs': Unravelling the environmental drivers controlling dominance and succession among diazotrophic and non-N2-fixing harmful cyanobacteria. Environ. Microbiol. 2016, 18, 316-324. [CrossRef]

24. Schindler, D.W. The dilemma of controlling cultural eutrophication of lakes. Proc. R. Soc. B Biol. Sci. 2012, 279, 4322-4333. [CrossRef]

25. Wan, L.; Chen, X.; Deng, Q.; Yang, L.; Li, X.; Zhang, J.; Song, C.; Zhou, Y.; Cao, X. Phosphorus strategy in bloom-forming cyanobacteria (Dolichospermum and Microcystis) and its role in their succession. Harmful Algae 2019, 84, 46-55. [CrossRef]

26. Rigosi, A.; Carey, C.C.; Ibelings, B.W.; Brookes, J.D. The interaction between climate warming and eutrophication to promote cyanobacteria is dependent on trophic state and varies among taxa. Limnol. Oceanogr. 2014, 59, 99-114. [CrossRef]

27. Tu, Q.Y.; Gu, D.X.; Yi, C.Q.; Xu, Z.R.; Han, G.Z. The Researches on the Lake Chaohu Eutrophication; Publisher of University of Science and Technology of China: Hefei, China, 1990. (In Chinese)

28. Jiang, Y.-J.; He, W.; Liu, W.-X.; Qin, N.; Ouyang, H.-L.; Wang, Q.-M.; Kong, X.-Z.; He, Q.-S.; Yang, C.; Yang, B. The seasonal and spatial variations of phytoplankton community and their correlation with environmental factors in a large eutrophic Chinese lake (Lake Chaohu). Ecol. Indic. 2014, 40, 58-67. [CrossRef]

29. Jiang, X.; Wang, S.; Zhong, L.; Jin, X.; Sun, S. Seasonal variation characteristics of algae biomass in Chaohu Lake. Environ. Sci. 2010, 31, 2056-2062. (In Chinese)

30. Guan, Y.; Zhang, M.; Yang, Z.; Shi, X.; Zhao, X. Intra-annual variation and correlations of functional traits in Microcystis and Dolichospermum in Lake Chaohu. Ecol. Indic. 2020, 111, 106052. [CrossRef]

31. Kong, X.; He, Q.; Yang, B.; He, W.; Xu, F.; Janssen, A.B.G.; Kuiper, J.J.; van Gerven, L.P.A.; Qin, N.; Jiang, Y.; et al. Hydrological regulation drives regime shifts: Evidence from paleolimnology and ecosystem modeling of a large shallow Chinese lake. Glob. Chang. Biol. 2017, 23, 737-754. [CrossRef]

32. APHA. Standard Methods for the Examination of Water and Wastewater; APHA-AWWA-WPCF: Washington, DC, USA, 1985.

33. Hu, H.; Wei, Y. The Freshwater Algae of China: Systematics, Taxonomy and Ecology; Science Press: Beijing, China, 2006.

34. Utermöhl, H. Zür Vervollkommung der quantitativen Erfassung des Planktons (mit besonderer Berucksichtigung des Ultraplanktons). Verh. Int. Ver. limnol. 1958, 5, 567-596. 
35. Hillebrand, H.; Dürselen, C.D.; Kirschtel, D.; Pollingher, U.; Zohary, T. Biovolume calculation for pelagic and benthic microalgae. J. Phycol. 1999, 35, 403-424. [CrossRef]

36. Wilson, S.E.; Cumming, B.F.; Smol, J.P. Diatom-salinity relationships in 111 lakes from the Interior Plateau of British Columbia, Canada: The development of diatom-based models for paleosalinity reconstructions. J. Paleolimnol. 1994, 12, 197-221. [CrossRef]

37. Mcdonald, K.E.; Lehman, J.T. Dynamics of Aphanizomenon and Microcystis (cyanobacteria) during experimental manipulation of an urban impoundment. Lake Reserv. Manag. 2013, 29, 103-115. [CrossRef]

38. Bormans, M.; Ford, P.W.; Fabbro, L. Spatial and temporal variability in cyanobacterial populations controlled by physical processes. J. Plankton Res. 2005, 27, 61-70. [CrossRef]

39. Zhang, M.; Shi, X.; Yang, Z.; Chen, K. The variation of water quality from 2012 to 2018 in Lake Chaohu and the mitigating strategy on cyanobacterial blooms. J. Lake Sci. 2020, 32, 11-20.

40. Kromkamp, J.; van den Heuvel, A.; Mur, L.R. Phosphorus uptake and photosynthesis by phosphate-limited cultures of the cyanobacterium Microcystis Aeruginosa. Br. Phycol. J. 1989, 24, 347-355. [CrossRef]

41. Li, Y.; Li, D. Competition between toxic Microcystis aeruginosa and nontoxic Microcystis wesenbergii with Anabaena PCC7120. J. Appl. Phycol. 2012, 24, 69-78. [CrossRef]

42. Chia, M.A.; Jankowiak, J.G.; Kramer, B.J.; Goleski, J.A.; Huang, I.S.; Zimba, P.V.; do Carmo Bittencourt-Oliveira, M.; Gobler, C.J. Succession and toxicity of Microcystis and Anabaena (Dolichospermum) blooms are controlled by nutrient-dependent allelopathic interactions. Harmful Algae 2018, 74, 67-77. [CrossRef] [PubMed]

43. Filstrup, C.T.; Downing, J.A. Relationship of chlorophyll to phosphorus and nitrogen in nutrient-rich lakes. Inland Waters 2017, 7, 385-400. [CrossRef]

(C) 2020 by the authors. Licensee MDPI, Basel, Switzerland. This article is an open access article distributed under the terms and conditions of the Creative Commons Attribution (CC BY) license (http://creativecommons.org/licenses/by/4.0/). 